\title{
Thermal performance of (organic and inorganic) multi PCM Encapsulated systems
}

Omar Yaseen Naife ${ }^{1}$, Prof. Dr. Fawziea M. Hussien ${ }^{2}$, Prof. Dr. Johain J. Faraj ${ }^{3}$

${ }^{1}$ Middle Technical University Engineering Technical College-Baghdad, Baghdad Iraq. Email : omaryaseen423@gmail.com

${ }^{2}$ Middle Technical University Engineering Technical College-Baghdad, Baghdad Iraq. Email: Fawizea_material@mtu.edu.iq

${ }^{3}$ Middle Technical University Engineering Technical College-Baghdad, Baghdad Iraq. Email: Johaintech@mtu.edu.iq

\begin{abstract}
The storing of energy is the imprisonment of energy at one time to use the similar for another time. This review paper treats with the approaches of thermal energy storage and its implementations in the neighborhood of solar water heating schemes in addition to scheme of solar air heating and the materials utilized to preserve that thermal energy efficiently. This paper delivers the theoretical information of appropriate and unwanted features of various phase change materials PCMs. The paper includes several approaches of thermal energy storage as, latent heat storage, sensible heat storage and thermo-chemical energy storage, concentrating mostly on (PCMs) as an arrangement of appropriate solution for usage of energy to fill the hole amid deliver and request to develop the effectiveness of energy of a scheme. Theoretical details have been shown in the paper. The numerical results show the temperature contour increases when the time of charging process increases, and the temperature contour decreases when the time of discharging process increases.
\end{abstract}

Keywords: PCMs; latent heat storage; thermal energy storage; thermochemical energy storage; organization of phase change materials; implementations of phase change material. 


\section{Introduction}

The chief task of the evolution of using the sources of renewable energy is the lag of time between the request and supply of energy. The energy storage denotes a faultless solution for reducing the influence of such lag of time. In general, the thermal energy can be stowed reasonably as well as latently. The density of the extraordinary-energy storage and almost the isothermal conduct of PCM through the procedures of charging and discharging make it a vigorous element of each system of the active storage of thermal energy [1]. (TES) being a broad field of technology which has been lengthy investigated in various industries as well as procedures. The new increase of the Solar Thermal Power in the previous ten years has made the academics and industrial verify its technical feasibility. Though such industrial services being too highly set up with a robust and dependable mechanisms for storing the thermal energy, they yet can be enhanced for gaining the effectiveness and reducing the costs [2]. Today, the phase change materials $s$ can be utilized in the TES uses for taking the solar thermal energy benefit within a passive manner. Because such reaction is Endothermic, PCMs absorb the heat. If the temperature reduces and attains the temperature of solidification, phase change materials vary the phase from the liquid to the solid. At such period, they relief the stowed heat because of the reaction being Exothermic [3].

Phase change materials can preserve and discharge a significant quantity of heat as a latent heat for the duration of conversion of phase via about 5-14 times upper than the sensible heat storage materials per unit volume. The researchers have been presented as progressive thermal storage materials in several building implementations to enhance the thermal load on a yearly basis [4]. One of the most considerable and important storage systems, are the Thermal Energy Storage (TES) systems. These systems come with two kinds, latent heat thermal energy storage, and sensible heat thermal energy storage and. A modern method has been proposed to use (PCM) in these schemes. Phase change materials have been commonly utilized in the latent heat storage systems LHSSs for applications of heat pumps, solar engineering, and spacecraft thermal control [5]. The systems of the parabolic trough collector utilize trough-shaped mirror reflectors for concentrating the sunlight onto the receiver tubes during which a thermal transfer fluid being heated to approximately $\left(400^{\circ} \mathrm{C}\right)$ and after that employed for producing the super-heated 
steam. Then, the heat is utilized for operating a traditional power cycle, for instant, throughout a Stirling engine or a steam turbine, see figure (1).

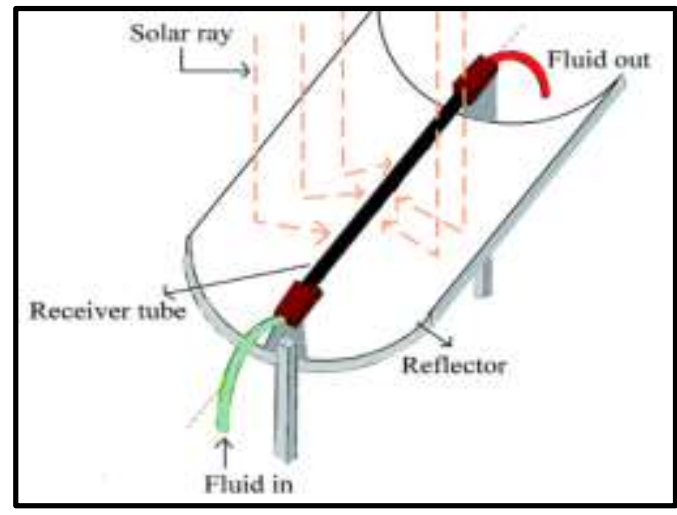

Figure (1): Schematic Diagram of a Parabolic Trough Collector [6]

\section{Thermal Energy Storage (TES)}

It can be described as impermanent TES at the low or elevated high temperatures. Such idea isn't fresh; it has been utilized and evolved for periods since it plays a significant part in the conservation of energy. The storage systems of thermal energy possess the prospective of creating the usage of thermal apparatus highly active, as well being a significant means to offset the mismatch between the accessibility and the need of the thermal energy. The elegant regimes are able to decrease the costs of the preliminary and upkeep as well as enhance the energy efficacy [7].

Depending on the manner that the heat being stowed, the storage of thermal energy can be categorized into [8]:

* Sensible heat: In the hot solids and liquids,

* Latent heat: In the vapor and melts, and

* Chemical heat: In the chemical pounds.

The classification of thermal energy storage technology depending upon the state criterion of the material of energy storage is evinced in figure (2). 


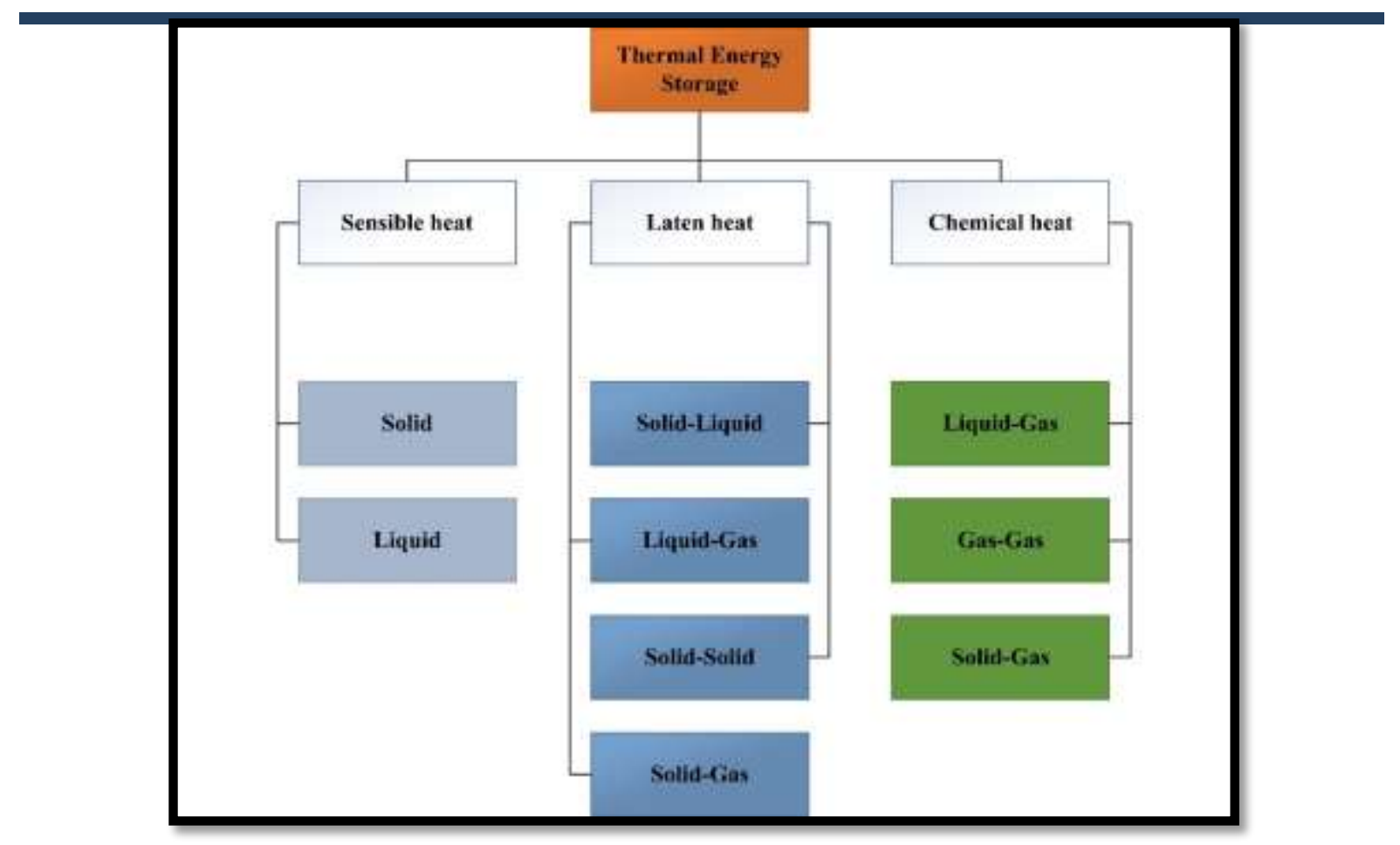

Figure (2): The classification of the thermal energy storage technology [9]

\section{A. Latent Heat Storage (LHS)}

system of LHS is founded on the heat of releasing or absorption once a storage material suffers a variation of phase from liquid to gas or solid to liquid or viceversa. It is an utmost attractive because of great storage energy density per unit mass in quasi-static procedure [10].

\section{B. Sensible Heat Storage (SHS)}

The systems of the (SHS) utilize the stored energy or the extracted energy via cooling or heating a solid or liquid, which doesn't vary its phase through such procedure, like the water, certain inorganic molten salts and the heat transfer oils, and the solid as rocks, refractory, and pebbles. The materials of energy storage for the (SHS) will not undergo the procedure of phase change if they stow the thermal energy. The merely procedure that such substances will undergo is the temperatures variation in a single phase. The systems of (SHS) being easier in the design than the latent heat or the systems of the thermo-chemical storage. Nevertheless, they experience the drawbacks of being larger in the size and are not able to stow or provide the energy at a fixed temperature $[10,11]$. 


\section{Thermo-chemical heat storage}

Thermochemical Heat Storage (THS), or Thermo-chemical storage (TCS) needs a reversible chemical reaction. Thermochemical Heat Storage is classified into three procedures: charging, storing and discharging. In the charging procedure, the heat absorbed from an energy source (e.g., usual energy sources), separates the thermochemical material $\mathrm{A}$ into the reactants $\mathrm{B}$ and $\mathrm{C}$ in an endothermic reaction [12].

\section{Grouping of phase change materials}

PCM that have their discharging/charging procedure within solid-liquid conversion class are categorized into three main groups: inorganic, organic, and eutectic phase change material. These groups are divided more into sub-groups. Organic phase change materials cover non-paraffin and paraffin materials via which the latter includes sugar alcohols, fatty acids, and glycols as sections. Inorganic phase change materials are categorized as molten salts, salt-hydrates, or metals. Furthermore, eutectic phase change materials are attained via mixing two or more inorganics, organics, or organic with inorganic PCMs. Phase change materials with their several groups have an extensive range of melting temperatures whereby each has an identified latent heat capacity of melting. This is the major variable to be taken into consideration whereas selecting an appropriate phase change material for an identified implementation. Actually, some features are essential to certify extreme thermal presentation. These features are kinetic, thermos-physical, chemical, environmental, and economical, and the list of these properties is offered in Figure 3. 


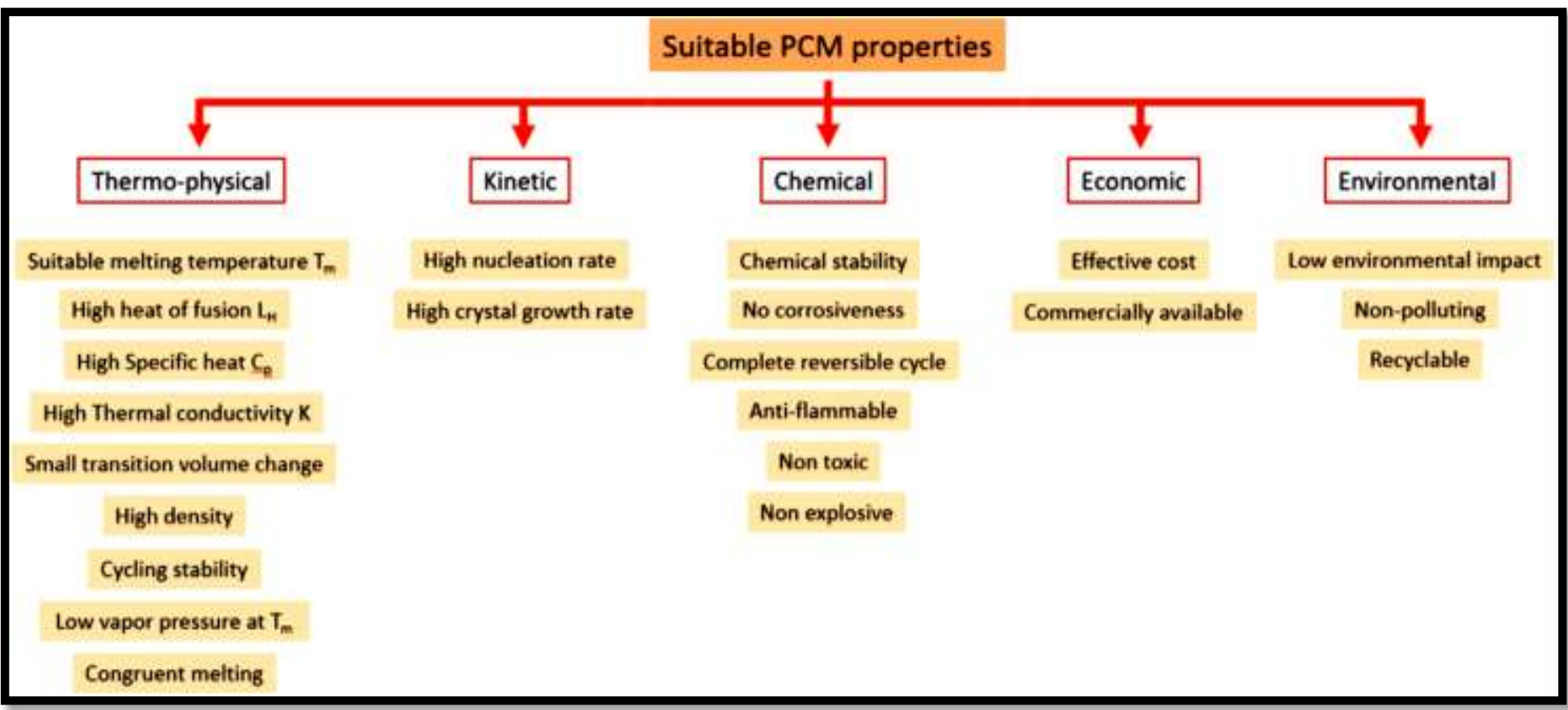

Figure (3): Suitable PCM required properties [13]

\section{Organic}

Three sub-kinds can be specified within the organic PCMs: fatty acids, paraffins, and polyethylene glycol. Generally, these compounds have good thermal features and suitable chemical steadiness. Consequently, it is seen how much of the research is presently associated to various types of usages of paraffin in structure components for buildings since their chemical stability eases the synthesis of materials and products' making [14].

\section{* Inorganic}

Inorganic solids phase change materials are capable to preserve/discharge heat energy in the solid phase by one or a grouping of energy storage methods for example conversions of crystallographic structure, order-disorder, conversions amid crystal and amorphous structure, especially, the first two approaches utilize big quantities of latent heat. One of the types of inorganic materials are metallic foams. They are described by low density, good stability, and great ratio coefficient, which rise their thermal conductivity in relation to nanoparticles. Nevertheless, the pores size has very little effect on the thermal conductivity [15]. 


\section{The eutectic}

The eutectic is the least composition of the melting of (2) or higher constituents that melt and freeze correspondingly creating a combination of constituent crystals through the crystallization. It continuously melts and freezes with no separation because they freeze to a close crystals combination, leaving a slight chance for the constituents to disperse. Upon melting the two constituents that dissolve concurrently, once more with the improbable parting [16].

\section{Heat Transfer Coefficient}

* For HTF and cold water:

$\mathrm{Nu}$ for fully developed turbulent flow can be expressed by means of [17]:

$$
N u=0.023 \operatorname{Re}^{0.8} \operatorname{Pr}^{n} \quad \mathrm{n}
$$

$\left\{\begin{array}{c}0.3 \text { for cold water during the cooling process } \\ .4 \text { for hot water during the heating process }\end{array}\right.$

The Reynold and Prandtl numbers can be calculated by the following formulas [2]. $R e=\frac{u \rho \mathrm{Dh}}{\mu}$

$$
\operatorname{Pr}=\frac{C p \mu}{k}
$$

Where, $(D h)$ is the hydraulic diameter for the rectangular tubes, and it can be calculated by the perimeter and the cross-sectional area.

$D_{h}=\frac{4 A}{P}$

The heat transfer coefficient for the hot and cold water [2] is:

$h_{w}=\frac{k N u}{D_{h}}$

The thermal properties of water can be found based on the bulk temperature, that is the arithmetic mean of temperatures at inlet and exit.

$T b=\frac{T_{w, \text { in }}+T_{w, \text { out }}}{2}$ 


\section{For PCM}

From the investigational data, experimental correlations were estimated for every particular geometry. These equations delivered the heat transfer coefficient for the natural convection in terms of the variance of the temperature of scheme. In vertical enclosure, the fluid near the hottest surface increases, and the fluid near the coolest surface drops. This initiates a rotational movement inside the case promoting the transfer of heat throughout the case. When the PCM melts, the buoyant force overwhelms the resistance of fluid and starts the usual convection currents. For a vertical rectangular enclosure, Berkovsky and Polevikov (1977) [17] proposed the following:

For $2<(\mathrm{L} / \mathrm{W})<10, \operatorname{Pr}<10^{5}$ and $\mathrm{Ra}_{\mathrm{L}}<10^{13}$,

$$
\mathrm{Nu}=.22\left(\frac{R a P r}{0.2+\operatorname{Pr}}\right)^{0.28}\left(\frac{\mathrm{w}}{\mathrm{L}}\right)^{0.25}
$$

Where, the Rayleigh number is definite as:

$R a=G r * \operatorname{Pr}=\frac{\mathrm{g} \beta\left(T_{c}+T_{\mathrm{h}}\right) \mathrm{wc}}{\mathrm{v}_{p c m}^{2}} \frac{\mu_{p c m} C p_{p c m}}{k_{p c m}}$

$\beta$ is the Coefficient of volume expansion is the density variation of that material having a temperature and defined as:

$\beta=\frac{1}{T_{f}}$

$T_{f}$ is the film temperature in Kelvin and can be calculated by the average between the hot $\left(T_{\mathrm{h}}\right)$ and the cold $\left(T_{\mathrm{c}}\right)$ sides of the enclosure.

$T f=\frac{T_{c}+T_{\mathrm{h}}}{2}$

$\mathrm{wc}$ is the characteristic length of the geometry taken as the width of the enclosure (m).

The heat transfer coefficient of the liquid PCM is evaluated by the effective thermal conductivity as it is the result of the product of the liquid thermal conductivity and Nusselt number [17]. 


$$
h_{\text {liq,pcm }}=\frac{K_{e f f}}{w_{\mathrm{c}}}=\frac{k_{l i q, p c m} N u}{w_{\mathrm{c}}}
$$

For solid phase of PCM, it can be calculated based on the equality of the conduction and convection heat transfer rates, which will produce the following equation.

$h_{\text {solid,pcm }}=\frac{K_{\text {soild,pcm }}}{w_{\mathrm{c}}}$

All the properties of PCMs in the liquidous and solidus states are evaluated at the film temperature, and the properties of the heat transfer fluids are also evaluated at the film temperature.

\section{Thermal Properties of Selected Materials \\ * Heat Transfer Fluid (water)}

The density, viscosity, specific heat and the thermal conductivity of the heat transfer fluid (water) can be estimated by the subsequent equations [18].

$$
\begin{aligned}
& \rho w=754.3079871+1.88132843 T_{b}-0.0035831 T_{b}^{2} \\
& \mu w=146039867076.91 T_{b}^{-5.74} \\
& C p w=5.476-0.008178 T_{b}+0.000013 T_{b}^{2} \\
& k=0.0223 T_{b}^{0.5802}
\end{aligned}
$$

\section{Sodium acetate trihydrate (SAT)}

Thermal properties of the Sodium Acetate Trihydrate (SAT) can be calculated by the following equations [19]:

$C_{p s}\left(\frac{J}{g K}\right)=1.43+2.03 \times 10^{-3} T_{f}$

$C_{p l}\left(\frac{J}{g K}\right)=2.96+1.51 \times 10^{-3} T_{f}$

$(265 \mathrm{~K}-365 \mathrm{~K})$ 
$k_{s}\left(\frac{w}{m \kappa}\right)=2.79-1.31 \times 10^{-2} T_{f}+1.88 \times 10^{-5} T_{f}^{2} \quad(240 \mathrm{~K}-325 \mathrm{~K})$

$k_{l}\left(\frac{w}{m K}\right)=.925-3.64 \times 10^{-3} T_{f}+6.62 \times 10^{-6} T_{f}^{2}(270 \mathrm{~K}-356 \mathrm{~K})$

$\rho_{s}\left(\frac{k g}{m^{3}}\right)=807+4.77 T_{f}-8.84 \times 10^{-3} T_{f}^{2} \quad(260 \mathrm{~K}-329 \mathrm{~K})$

(21)

$\rho_{l}\left(\frac{\mathrm{kg}}{\mathrm{m}^{3}}\right)=-19900+170 T_{f}-0.354 T_{f}^{2}+1.76 \times 10^{-5} T_{f}^{3}-(280 \mathrm{~K}-360 \mathrm{~K})$

$1.8 \times 10^{-7} T_{f}^{3}+1.35 \times 10^{-9} T_{f}^{5}$

\section{The Paraffin Wax}

Thermal properties of the Sodium Acetate Trihydrate (SAT) can be calculated by the following equations [23] and [28]:

$\rho_{l}\left(\frac{k g}{m^{3}}\right)=833.6-.6398 T_{f} \quad(333 \mathrm{~K}-382 \mathrm{~K})$

$\rho_{s}\left(\frac{k g}{m^{3}}\right)=941.72-1.1551 T_{f} \quad(283 \mathrm{~K}-331 \mathrm{~K})$

$C_{p l}\left(\frac{J}{g K}\right)=2.0179+.0016 T_{f} \quad(333 \mathrm{~K}-363 \mathrm{~K})$

$C_{p s}\left(\frac{J}{g K}\right)=1.7169+.0097 T_{f} \quad(263 \mathrm{~K}-283 \mathrm{~K})$

$k_{s}\left(\frac{W}{m \cdot K}\right)=3 \times 10^{-5} T_{f}^{2}-.0018 T_{f}+0.2491 \quad(273 \mathrm{~K}-233 \mathrm{~K})$

$k_{l}\left(\frac{W}{m K}\right)=.191+.0011 T_{f}-6 \times 10^{-6} T_{f}^{2} \quad(243 \mathrm{~K}-373 \mathrm{~K})$

\section{Stearic acid (SA) Fatty Acids}

Specific heat of stearic acid in the two states, solid and liquid was estimated in term of temperature (degrees C) as follow [22]:

Solid state $\quad C p=0.4272 \mathrm{q}-0.0018 \mathrm{~T}_{f} \quad\left(-120^{\circ}\right.$ to $\left.65^{\circ} \mathrm{C}\right)$

Liquid state $\quad C p=0.4266-\}-0.0018 \mathrm{~T}_{f} \quad\left(70^{\circ}\right.$ to $\left.78^{\circ} \mathrm{C}\right)$ 
Thermal conductivities of stearic acid in the two states, solid and liquid were calculated as follow:

Solid state $\quad k=0.42\left[1-.00295\left(T_{f}-290\right)\right] \quad(290 \mathrm{~K}$ to $340 \mathrm{~K})[23]$

Liquid state $\quad k=0.2185-0.0008 \mathrm{~T}_{f}$

$\left(70^{\circ}\right.$ to $\left.148^{\circ} \mathrm{C}\right)[24]$

Density of stearic acid was calculated by the following equation concluding that both the solid and liquid states with temperature varied from 20 to $110^{\circ} \mathrm{C}$ [25]:

$$
\rho\left(\frac{k g}{m^{3}}\right)=1041 T_{f}^{-0.041}
$$

\subsection{NUMERICAL RESULTS:}

In present study, three types of PCMs are used; Sodium Acetate Trihydrate (SAT), Fatty acids (stearic acids) and paraffin wax, which being the materials that can encounter such needed characteristics. Despite the fact that the fatty acids have a varying level of toxicity, the salt hydrates cause a corrosion in the metal containers, while the Paraffin waxes are safe and non-corrosive. Their points of melting points being between $\left(58^{\circ} \mathrm{C}\right)$ and $\left(70^{\circ} \mathrm{C}\right)$, which are in the range of temperature of the solar energy regimes.

\subsubsection{Tests:}

The first numerical test was conducted based on the $0.5 \mathrm{~L} / \mathrm{min}$ water flow rate. The charging process lasts for 7 hours. The capsules' temperature during the charging process are shown in figures below. We noticed that in 1/11/2020 the temperature contour increases when the time of charging process increases, whereas the temperature contour is at a range from 306.3 to $298.8 \mathrm{~K}$ at the first interval from 9 to $11 \mathrm{AM}$, from 343.9 to $301.1 \mathrm{~K}$ at the second interval from 11:30 AM to 1:30 $\mathrm{PM}$, and from 346 to $303.7 \mathrm{~K}$ at the third interval from 2 to 4 PM. See figures (4), (5), and (6). 


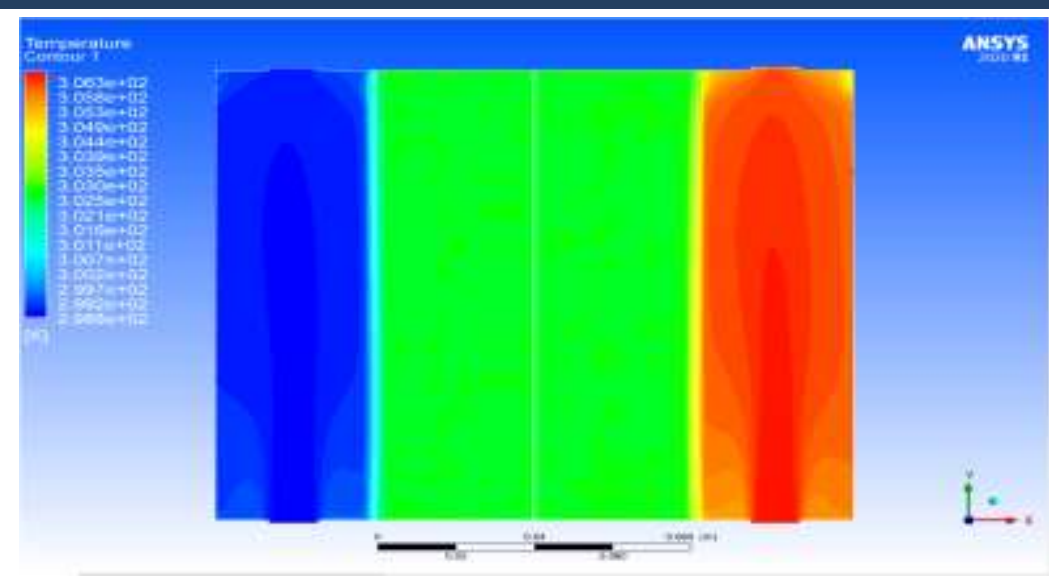

Figure (4): The temperature contour is at a range from 306.3 to $298.8 \mathrm{~K}$ at the first interval from 9 to $11 \mathrm{AM}$

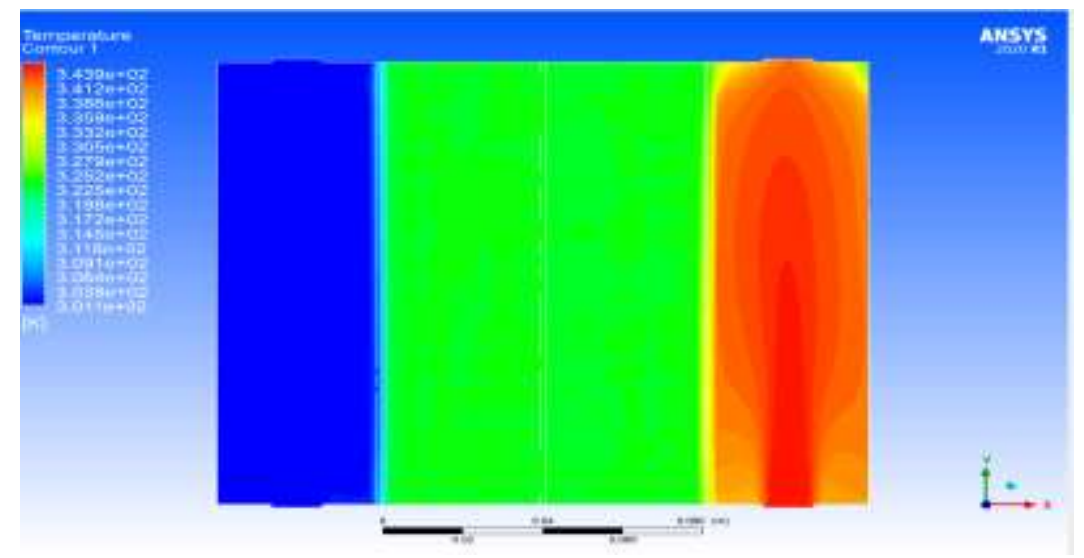

Figure (5): The temperature contour is at a range from 343.9 to $301.1 \mathrm{~K}$ at the second interval from 11:30 AM to 1:30 PM

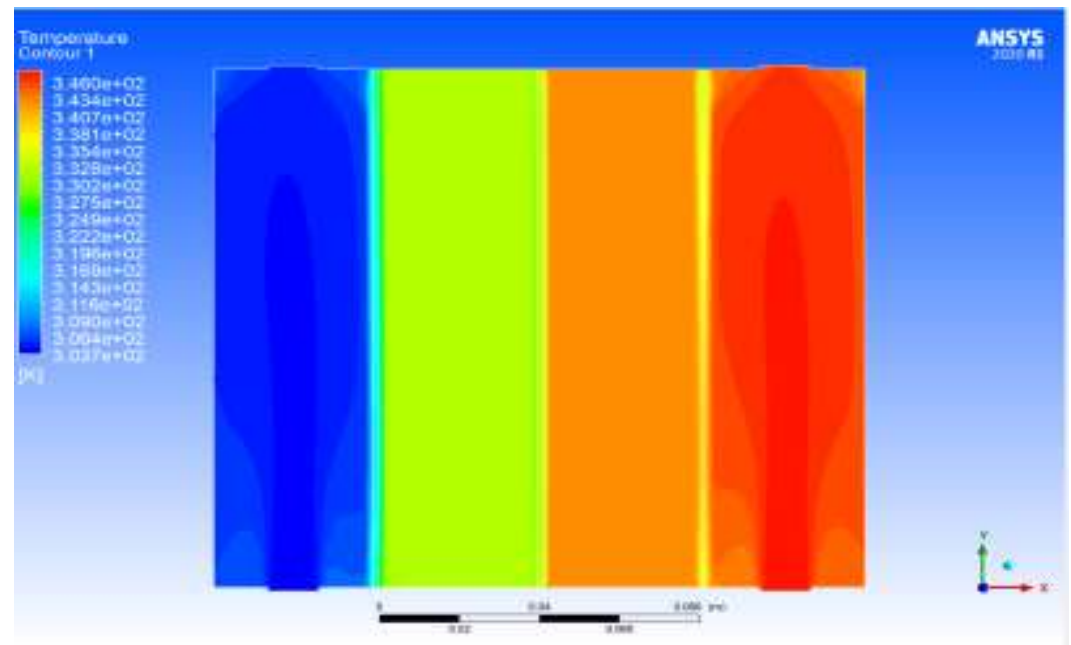

Figure (6): The temperature contour is at a range from 346 to $303.7 \mathrm{~K}$ at the third interval from 2 to $4 \mathrm{PM}$ 
On 2/11/2020 a test was performed with a $1.5 \mathrm{~L} / \mathrm{min}$ water flow rate for both hot and cold sides. The charging process lasts for 6:30 hours with an average hot-water temperature difference of $2.16{ }^{\circ} \mathrm{C}$. We noticed that in $2 / 11 / 2020$, the temperature contour is at a range from 307.6 to $298.6 \mathrm{~K}$ at the first interval from 9 to $11 \mathrm{AM}$, from 342 to $298.8 \mathrm{~K}$ at the second interval from 11:30 AM to 1:30 PM, and from 346.1 to $302 \mathrm{~K}$ at the third interval from 2 to 3:30 PM. See figures (7), (8), and (9).

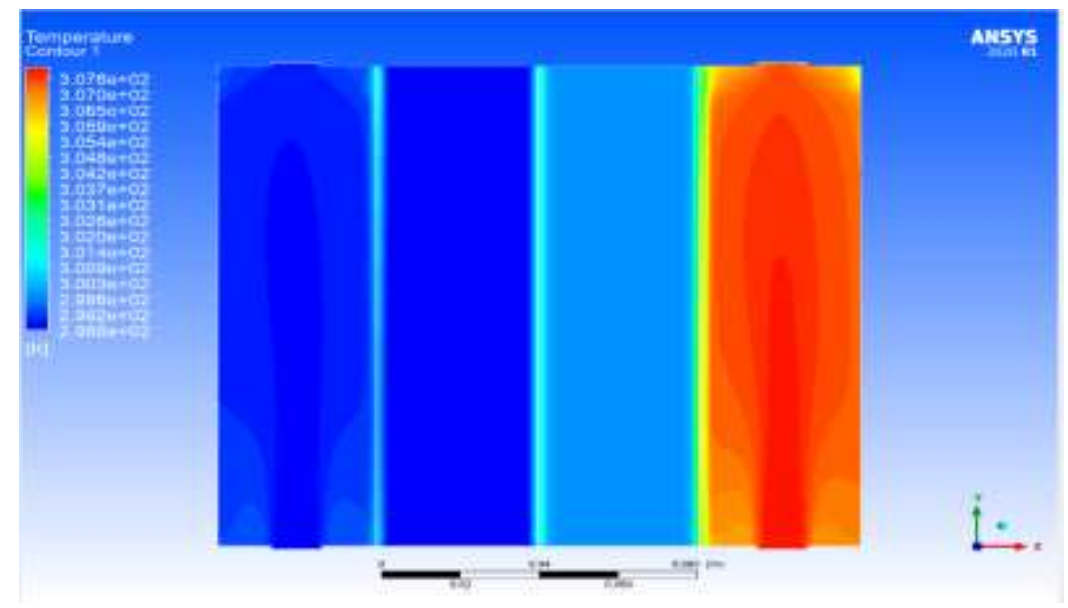

Figure (7): the temperature contour is at a range from 307.6 to $298.6 \mathrm{~K}$ at the first interval from 9 to $11 \mathrm{AM}$

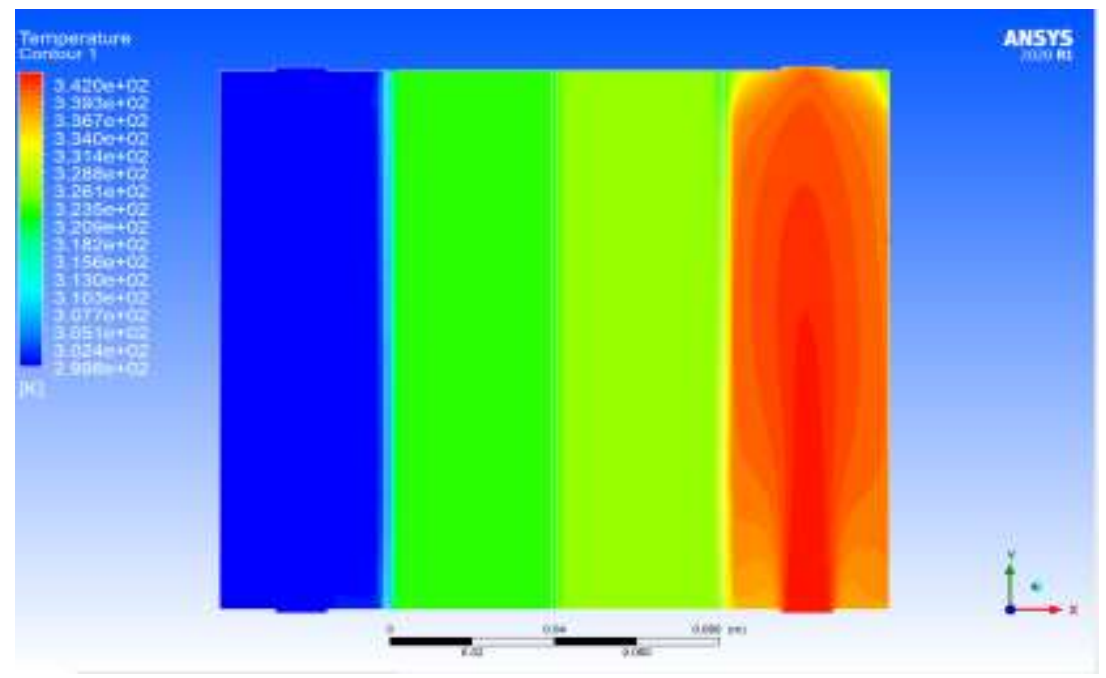

Figure (8): the temperature contour is at a range from 342 to $298.8 \mathrm{~K}$ at the second interval from 11:30 AM to 1:30 PM 


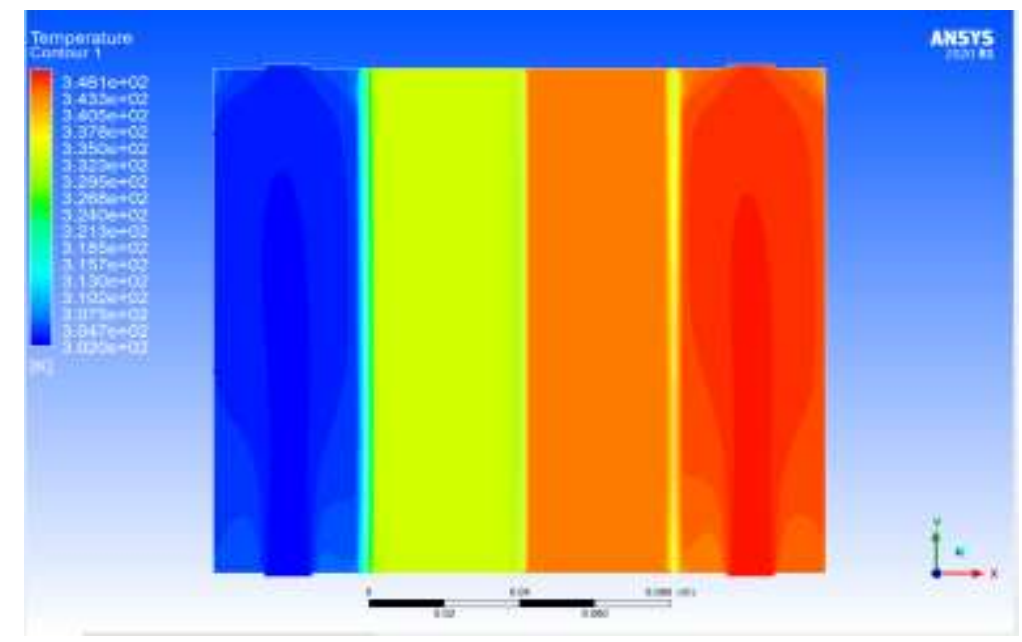

Figure (9): the temperature contour is at a range from 346.1 to $302 \mathrm{~K}$ at the third interval from 2 to $3: 30 \mathrm{PM}$.

\section{Conclusions}

Thermal energy storage (TES), generally named heat and cold storage, permits heat or cold to be utilized later. Energy storing can be classified into several groups, nevertheless this article concentrates on thermal energy storing since this is a main technology in energy schemes for preserving and rising energy efficiency. By the way, the significance of energy storing was examined, and it was described how though using several technologies, thermal energy can be absorbed and preserved for a later utilize. In specific, thermal energy containing latent heat storage, sensible heat storage, and thermochemical energy storage schemes were methodically investigated. It was clarified that how via using certain physical and chemical methods, thermal energy in term of latent and sensible heat can be deal with and preserved. Additionally, the basic factors defining the dynamics of conversion in the thermal storage schemes were clarified and various necessities for collection of various storage materials were termed. Incidentally, the utilizing of phase change materials was exposed to be a feasible solution for effective storage of thermal energy. 


\section{References}

[1] C. S. Ioan Sarbu, "A Comprehensive Review of Thermal Energy Storage," mdpi:Sustainability, 2018.

[2] B. Muñoz-Sánchez, I. Iparraguirre-Torres, V. Madina-Arrese, U. IzagirreEtxeberria, A. Unzurrunzaga-Iturbe, and A. García-Romero, "Encapsulated High Temperature PCM as Active Filler Material in a Thermocline-based Thermal Storage System," Energy Procedia, vol. 69. pp. 937-946, 2015, doi: 10.1016/j.egypro.2015.03.177.

[3] T. Kousksou, P. Bruel, A. Jamil, T. El Rhafiki, and Y. Zeraouli, "Energy storage: Applications and challenges," Sol. Energy Mater. Sol. Cells, 2013, doi: 10.1016/j.solmat.2013.08.015.

[4] Q.Al-Yasiri, and M. Szabó, "Performance Assessment of Phase Change Materials Integrated with Building Envelope for Heating Application in Cold Locations," European Journal of Energy Research, V o 1: 1, I s s u e: 1, F e b r u a r y 2021.

[5] Wisam H., Fawziea M., and Johain J. "Energy and Exergy Analysis of a Multi-PCM Solar Storage System," Journal of Advanced Research in Fluid Mechanics and Thermal Sciences, vol: 78, Issue: 1, p.p: 60-78, (2021)

[6] S. Dabiri and M. F. Rahimi, "Basic introduction of solar collectors and energy and exergy analysis of a heliostat plant," 3rd Int. Conf. Exhib. Sol. Energy, 2016.

[7] P. Diaz, "Analysis and Comparison of different types of Thermal Energy Storage Systems: A Review," Journal of Advances in Mechanical Engineering and Science (JAMES), vol. 55, no. IV, 2016.

[8] “Analysis_and_Comparison_of_different_types_of_Ther.pdf.".

[9] A. Haselbacher, "An Overview of Thermal Energy Storage," No. January $2012,2015$.

[10] S. Ali, and S. Deshmukh," An overview: Applications of thermal energy storage using phase change materials," Materials Today: Proceedings" 2020 . 
[11] C. Sunliang, "State of the Art Thermal Energy Storage Solutions for High Performance Buildings.” p. 201, 2010.

[12] D. Enescu, G. Chicco, R. Porumb, and G. Seritan," Thermal Energy Storage for Grid Applications: Current Status and Emerging Trends," Energies, vol: 13, issue: 340, 2020.

[13] K. Faraj, M. Khaled, J. Faraj, F. Hachem, and C. Castelain," Phase change material thermal energy storage systems for cooling applications in buildings: A review," Renewable and Sustainable Energy Reviews, (2020).

[14] J.Reyez-Araiza et al., Thermal Energy Storage by the Encapsulation of Phase Change Materials in Building Elements-A Review," journal/materials, 2021.

[15] H. Jouhara, A. Żabnieńska-Góra, N. Khordehgah, D. Ahmad, and $T$. Lipinski," Latent Thermal Energy Storage Technologies and Applications: A Review," International Journal of Thermofluids (2020)

[16] S. M. Hasnain, "Review on sustainable thermal energy storage technologies, part I: Heat storage materials and techniques," Energy Convers. Manag., vol. 39, no. 11, pp. 1127-1138, 1998.

[17] P. Salunkhea and D. J. Krishna, "Investigations on latent heat storage materials for solar water and space heating applications," J. Energy Storage, 2017.

[18] A. J. G. and D. Y. A. Cengel, "Heat and Mass Transfer: Fundamentals and Applications," McGraw-Hill Educ.

[19] M. Nnamchi, Stephen Ndubuisi, and Nnamchi, Onyinyechi \& Onuorah and V. Sangotayo, Emmanuel \& Gabriel, "Modelling and Simulation of Heat Transfer through the Finned Hollow Cylindrical Surfaces of an Insulation Testing Rig," World J. Model. Simul., 2019.

[20] M. K. and K. Mahkamov, "Salt hydrates as latent heat storage materials: Thermophysical properties and costs," olar Energy Mater. Sol. Cells, 2016.

[21] and J. Š. N. Ukrainczyk, S. Kurajica, "Thermophysical Comparison of 
FiveCommercial ParaffinWaxes as Latent Heat StorageMaterials," Chem. Biochem. Eng, pp. 129-137, 2010.

[22] T. S. and D. at V. Temperatures, "W. F. Seter And Kura and Iitsu Iuouye," Ind. Eng. Chem., 1935.

[23] W. S. Singleton, T. L. Ward, and F. G. Dollear, "Physical Properties of Fatty Acids.Thermal Properties of Stearic Acid I. Some Dilatometric andThermal Properties of Stearic Acid in Two Polymorphic Forms," J. TItE Am. OIL ChIEMISTS' Soc., 1980.

[24] U. Bayram, S. Akso“z, and N. Maras,1, "Temperature dependency of thermal conductivity of solid phases for fatty acids," 2014.

[25] M. S. D. Rozanna, T. G. Chuah, A. Salmiah, and Thomas S. Y. Choong, "Fatty Acids as Phase Change Materials (PCMs) for Thermal Energy Storage: A Review," NTERNATIONAL J. GREEN ENERGY, vol. 1, no. 4, pp. 495-513, 2004.

[26] O.-A. G.-R. and L.-J. L.-G. Diana-Carolina Cruz-Forero, "Calculation of thermophysical Properties of Oils and Triacylglycerols Using an Extended Constituent Fragments Approach," CT \& F - Ciencia, Tecnol. y Futur., 2012. 